\title{
FunCIONAMENTO PSÍQUiCO E MANEJO CLÍNICO DE PACIENTES SOMÁTICOS: REFLEXŌES A PARTIR DA NOÇÃO DE DESAFETAÇÃO
}

\author{
Juliana Pereira Landim Clemente* \\ Rodrigo Sanches Peres**
}

\section{ResUMo}

O presente estudo tem como objetivo apresentar um panorama, em termos teóricos e clínicos, da concepção psicossomática de Joyce McDougall. A noção de desafetação será utilizada como operador conceitual básico. Trata-se de um distúrbio da economia afetiva típico de pacientes somáticos, o qual promove uma incapacidade quase total em manter contato com as emoções próprias e alheias. Dentre outras especificidades da clínica psicanalítica com pacientes somáticos, destaca-se que ao profissional será imposto o desafio de funcionar como um filtro - sendo, assim, capaz de regular o afluxo de excitações, que tende a desencadear descargas corporais em função da inviabilidade, associada à desafetação, e de recorrer às palavras para torná-lo dizível.

Palavras-chave: psicossomática; psicanálise; psicologia clínica.

\section{Abstract \\ PSYCHIC FUNCTIONING AND CLINICAL HANDLING OF SOMATIC PATIENTS: REFLEC- TIONS STARTING FROM THE DISAFFECTION NOTION \\ The aim of this article is to show a theorical and clinical view of the psychosomatic conceptions of Joyce McDougall. The notion of disaffection will be used as a conceptual basic}

* Psicóloga, aluna do curso de especialização em Psicoterapias de Orientação Psicanalítica da Universidade Federal de São Carlos (UFSCar).

** Psicólogo, Mestre e Doutor em Psicologia pela Universidade de São Paulo (USP), Especialista em Psicologia Clínica pelo Conselho Federal de Psicologia (CFP), Professor Adjunto da Universidade Federal de Uberlândia (UFU). 
operator. It is a disturbance of the affective economy typical of somatic patients, which promotes an almost total incapacity to keep contact with their own emotions and someone else's. Among others specialities of the clinical psychoanalysis with somatic patients, the professional will be obliged to work as a filter capable to regulate the affluence of excitements that tends to unchain corporal discharges because the impossibility, associated to the disaffection, to use words to make them speakable.

Keywords: psychosomatics; psychoanalysis; clinical psychology.

\section{INTRODUÇÃO}

Durante sua passagem por Paris, no final do século XIX, Freud verificou, nas histéricas do Hospice de la Salpêtrière, que desejos de natureza sexual recalcados eram inscritos no corpo mediante o emprego inconsciente de um mecanismo psíquico até então desconhecido. Por essa razão, afirmou que "[...] na histeria, a representação incompatível é tornada inócua pela transformação de sua soma de excitação em alguma coisa somática. Para isso eu gostaria de propor o nome de conversão" (Freud, [1894a] 1996: 56). O até então eminente neurologista evidenciou, assim, que as doenças orgânicas não são decorrentes apenas de agentes biológicos e que o corpo é susceptível às vicissitudes da mente.

Vale mencionar também que Freud já havia concluído que "[...] a paralisia histérica comporta-se como se a anatomia cerebral não existisse. A histeria nada sabe sobre a anatomia cerebral" ([1893] 1996: 238). Partindo desse princípio, Volich (1998) defende que o corpo histérico - acometido por sintomas que apresentam uma relação metafórica com uma representação recalcada e que não respeitam a distribuição dos nervos - colocou o pai da psicanálise no limite de seus conhecimentos médicos e o levou a fundar a noção de uma "anatomia imaginária" que, distanciando-se do materialismo vigente na época, subverteu a fisiologia.

Logo, torna-se patente que Schiller (2003) tem justificativas consistentes para propor que "o nascimento da psicanálise foi, em parte, uma reação ao poder extremo adquirido pela medicina moderna, que passou a tratar os pacientes como organismos à deriva, ao sabor das leis naturais" (Schiller, 2003: 30). Afinal, Freud mostrou, quando da descrição da conversão, que a atenção dos médicos deveria se voltar para o doente e não para a doença em si - visto que o corpo, não raro, transcreve uma história misteriosa que pode ser decifrada e traduzida em palavras, mediante a identificação daquilo que o recalcamento ocultou da linguagem e a conversão transformou em um sintoma dotado de valor simbólico. 
Deve-se salientar ainda que, para Roudinesco (1986), a descrição da conversão postula a existência de um pensamento desvinculado da consciência e, consequentemente, de uma realidade psíquica distinta da realidade material e que não é pautada pela lógica estabelecida pelo sistema perceptivo-consciente. A propósito, Freud sinalizou isso quando, já na primeira década do século XX, observou que os ataques histéricos

nada mais são do que fantasias inconscientes exteriorizadas por meio da conversão: quando os sintomas são somáticos, com frequência são retirados do círculo das mesmas sensaçôes sexuais e inervações motoras que originalmente acompanhavam as fantasias quando estas ainda eram inconscientes (Freud, [1908] 1996: 151).

As proposições freudianas provocaram uma mudança de paradigma, ao superar o reducionismo biológico imposto pela tradição cartesiana. Isto inspirou outros autores em tentativas de identificação dos determinantes emocionais das doenças orgânicas. As tentativas pioneiras de Sándor Ferenczi e Georg Groddeck, entretanto, se revelaram pouco promissoras. Ocorre que o primeiro sustentava que o inconsciente teria a capacidade de se "materializar", adquirindo um status físico graças à corporificação do simbólico promovida pela conversão (Ferenczi, [1940] 1988). O segundo, por seu turno, aproximava os sintomas orgânicos das produçōes oníricas, atribuindo-lhes um sentido manifesto e outro latente (Groddeck, [1917] 1992).

Não obstante, nas últimas décadas, diversos psicanalistas contemporâneos, como observa Peres (2006), têm se mostrado atentos à ocorrência de sintomas somáticos que não apresentam as distorções características das formações de compromisso simbólicas. Entretanto, de alguma maneira, se encontram relacionados a determinantes emocionais. Desse modo, vêm utilizando o modelo etiológico das neuroses atuais na investigação das complexas interações que se estabelecem entre a mente e o corpo. Por essa razão, Laplanche e Pontalis ([1982] 2000: 301) afirmaram que tal modelo "[...] leva diretamente às concepções modernas sobre as afecções psicossomáticas".

Sabe-se, de acordo com a psicopatologia psicanalítica clássica, que os sintomas físicos das neuroses atuais (neurose de angústia, neurastenia e hipocondria) não são decorrentes da conversão, mas sim da ação de processos que, prescindindo de mediação psíquica, não podem ser considerados uma formação de compromisso simbólico. Logo, as referidas condições se opõem, do ponto de vista sintomatológico, não apenas à histeria, mas também às demais psicopatologias - fobias, 
obsessões e psicoses - então chamadas, na teorização freudiana, de psiconeuroses (Horn \& Almeida, 2003).

Freud esboçou essa oposição ao afirmar, antes mesmo da virada do século XIX, que na neurose de angústia e na neurastenia "[...] a fonte de excitação, a causa precipitante do distúrbio, reside no campo somático, e não no psíquico, como ocorre na histeria e na neurose obsessiva" (Freud, [1895] 1996: 114). A hipocondria foi incluída na classe das neuroses atuais posteriormente. Reconhecendo que o ego poderia patologicamente se apresentar como o objeto da libido, Freud ([1911] 1996) sugeriu que caberia entender o quadro clínico em pauta como um equivalente somático da paranoia; associado, portanto, a um tipo de atividade representativa filogeneticamente anterior à simbolização.

Joyce McDougall, psicanalista neozelandesa radicada na França, é uma das principais adeptas da utilização do modelo etiológico freudiano das neuroses atuais no campo da psicossomática. Conforme Peres (2005), a autora possibilitou forjar novas e instigantes hipóteses sobre as facetas psíquicas das doenças orgânicas. Ela se sobressai também por articular aproximações entre autores franceses e anglo-saxões, admitindo a pluralidade em termos teóricos e clínicos que atualmente caracteriza a psicanálise. Além disso, McDougall mantém um compromisso com a própria verdade, de modo que não hesita em repensar suas próprias concepções sempre que considera oportuno fazê-lo (Ceccarelli, 1997).

O presente estudo tem como objetivo apresentar um panorama da concepção psicossomática de McDougall e discutir algumas de suas implicações para a clínica psicanalítica com pacientes somáticos. Antes de tudo, é preciso esclarecer que serão agrupados sob essa rubrica portadores de doenças orgânicas para as quais se admite uma relação com aspectos emocionais e determinados acontecimentos vitais a ponto de possibilitar o acesso por via psicológica a sua essência estruturante, partindo da definição de Santos Filho (1993). Tal definição coloca em relevo os fatores psíquicos associados ao processo saúde-doença, mas, vale destacar, reconhece a multifatorialidade que o caracteriza.

\section{DesenVolvimento}

Para os fins do presente estudo, a noção de desafetação será utilizada como operador conceitual básico. McDougall (1983) forjou essa noção para fazer referência a um distúrbio da economia afetiva, típico de pacientes somáticos, após perceber que muitos deles apresentam uma incapacidade quase total de manter contato com as emoções próprias e alheias. As palavras, assim, ficam desvinculadas 
de seu sentido simbólico, ligando-se, como consequência, à concretude. A autora esclarece que isso ocorre, essencialmente, porque esses indivíduos vivenciaram precocemente emoções de grande poder disruptivo, as quais expulsaram defensivamente do campo da consciência.

Segundo Bunemer (1995), a desafetação leva o indivíduo a encontrar dificuldades para apreender contrastes emocionais e discriminar matizes afetivos. Logo, fomenta vínculos afetivos pouco consistentes. No entanto, relaçôes simbióticas podem ser implementadas em situações de sofrimento psíquico. Esse fenômeno seria uma tentativa de se fundir ao outro, reimplementando uma condição de indiferenciação, supostamente protetora, equivalente àquela que se observa nos primeiros meses de vida. Quando esporádico, esse tipo de recurso defensivo pode se mostrar funcional. Se recorrente, leva o sujeito a abrir mão da plena posse de si mesmo, comprometendo a identificação dos limites corporais (McDougall, 2001).

Para McDougall, a uma tendência a

[...] ejetar do psiquismo percepções, pensamentos, fantasias e outras ocorrências de natureza psicológica (frequentemente criadas por situações banais no mundo exterior, porém carregadas de dor mental para o indivíduo, registradas, mas não reconhecidas como tais) pode produzir, no adulto, uma regressão a respostas somáticas ao invés de uma resposta psicótica (McDougall, 1991: 116).

Segundo essa perspectiva, é possível concluir que a desafetação corresponde a uma problemática pré-neurótica, intimamente associada a um empobrecimento extremo da capacidade de simbolização. Na sequência da afirmação precedente, a autora sustenta que "há uma dissociação entre a representação da palavra e a representação da coisa, o que faz com que os sinais de angústia se tornem equivalentes de uma representação da coisa, destacada da representação da palavra que daria sentido à experiência” (McDougall, 1991: 116).

Vale destacar que, como esclarecem Laplanche e Pontalis ([1982] 2000), a representação de coisa resulta do investimento de imagens mnésicas de coisas ou de traços mnésicos derivados. A representação de palavra se encontra relacionada à verbalização. A ligação entre uma e outra caracteriza o sistema pré-consciente/ consciente; ao passo que o sistema inconsciente compreende apenas a representação de coisa.

A desafetação seria, então, correlativa a um mecanismo de defesa que, em contraste com a repressão e o recalque, respectivamente, não se emprega de modo consciente e não transforma o conteúdo excluído em material inconsciente. Todavia, se assemelha, em seus aspectos principais, a uma operação psíquica identificada 
desde os primórdios da psicanálise: o repúdio para fora do ego (Verwerfung). Trata-se, para Freud, de "[...] uma espécie de defesa muito mais poderosa e bemsucedida. Nela, o ego rejeita a representação incompatível juntamente com seu afeto e se comporta como se a representação jamais tivesse lhe ocorrido" (Freud, [1894a] 1996: 64).

$\mathrm{Na}$ teorização psicanalítica pós-freudiana, o repúdio para fora do ego geralmente é entendido como uma defesa específica das psicoses, pois se desdobra no surgimento de fenômenos alucinatórios e delirantes. Lacan ([1966] 1992), a propósito, partiu desse princípio para propor que a rejeição do falo como significante do complexo de castração desempenha papel central na etiologia desse tipo de entidade nosográfica. No entanto, optou, para fazer referência a essa rejeição primordial, por empregar o termo francês forclusion ("forclusão" em português) como equivalente do verbete alemão Verwerfung, cuja tradução mais adequada para a língua portuguesa seria, segundo a tradução da obra de Laplanche e Pontalis ([1982] 2000), "repúdio" ou "rejeição".

Todavia, na desafetação o repúdio para fora do ego fomenta uma espécie de forclusão dos afetos, ressomatizando-os como consequência. Ocorre que, para McDougall (1989: 130), "o afeto ao qual falta toda e qualquer compensação à sua perda corre o risco de ser cindido no seio de sua própria estrutura”. À semelhança das pulsões, os afetos são entendidos como algo que se situa no limite entre o somático e o psíquico. Por essa razão, resta aos afetos tolhidos de sua significação apenas uma dimensão orgânica que buscará expressão a todo custo. Ampliando uma metáfora tradicionalmente utilizada na teorização psicanalítica para fazer referência à histeria, a autora em pauta sugere que essa expressão ocorrerá mediante o desenrolar de um drama no teatro do corpo.

Dessa maneira, deduz-se que McDougall, ao desvincular o repúdio para fora do ego das psicoses, identifica a existência de um quarto destino para os afetos e, assim, ousadamente delineia um novo horizonte para a teorização psicanalítica. Afinal, para Freud ([1894b] 1996), os afetos, quando desligados das representaçôes, são convertidos, deslocados ou transformados, a exemplo do que ocorre, respectivamente, na histeria, na neurose obsessiva e na neurose de angústia ou na melancolia. A possibilidade de um indivíduo atacar impiedosamente suas emoções com o intuito de destruir as significações a elas relacionadas e, como consequência, desvitalizar seu mundo interno não foi vislumbrada pelo pai da psicanálise.

Mas quais são as implicações clínicas da concepção psicossomática de McDougall? Antes de responder essa questão, faz-se necessário esclarecer que a autora alerta que a psicanálise pode se mostrar pouco indicada nos casos em que o paciente apresenta dificuldades acentuadas para refletir sobre os fatores associados ao próprio 
adoecimento, uma vez que a mobilização afetiva intrínseca ao processo terapêutico é capaz de desempenhar um papel desestruturante, e não reorganizador, como seria de se esperar. A propósito, essa contraindicação também parece pertinente às psicoterapias de orientação psicanalítica, segundo Aisenstein (2005).

Como aponta McDougall (1991), o fato de um indivíduo teoricamente poder se beneficiar da psicanálise não o torna efetivamente um candidato à mesma - ou às psicoterapias de orientação psicanalítica, poder-se-ia acrescentar. Mais do que isso, o sujeito deve ser capaz de reconhecer a existência do próprio sofrimento psíquico e se mostrar disposto a tentar compreender seus determinantes inconscientes. Além disso, é imprescindível a existência de uma estrutura egoica minimamente organizada, capaz de suportar as angústias inerentes à situação analítica. Por fim, o sujeito deve estar pronto para receber ajuda, ou seja, para se colocar em uma situação de dependência, sem temer a frustração potencialmente intrínseca a qualquer relação interpessoal.

Iniciado o processo terapêutico, McDougall (1991) defende que ao profissional impor-se-á o desafio de funcionar como um filtro - sendo capaz de regular o afluxo de excitações do qual o paciente somático tende a se livrar apelando à descarga corporal, por não ter acesso às palavras que poderiam torná-lo dizível. Trata-se, em última instância, de desempenhar a função materna, sobretudo mediante a decodificação de uma modalidade de comunicação cuja impregnação afetiva é escassa. Esse procedimento se justifica porque, conforme sustenta a autora, a desafetação tem como principal fator etiológico perturbações precoces na díade mãe-bebê.

Essa hipótese parte do princípio de que a figura materna tem como principal tarefa proteger seu bebê das tensões provenientes do exterior, exercendo uma função análoga àquela que, na idade adulta, cabe ao sistema para-excitaçôes. Para tanto, deve interpretar a comunicação primitiva e nomear os estados afetivos do mesmo, promovendo a progressiva dessomatização do aparelho mental. $\mathrm{O}$ adequado desempenho dessa tarefa subsidia o acesso do bebê à palavra e facilita o desenvolvimento da capacidade de simbolização. Caso contrário, seus sinais pré-verbais permanecerão, conforme Peres (2006), distantes de qualquer código linguístico.

Desenvolvendo esse raciocínio, é possível afirmar que o profissional que aceita se enveredar pelos tortuosos meandros da clínica psicanalítica com pacientes somáticos deve se preocupar em promover a introjeção de uma figura materna benevolente. No entanto, tais pacientes, muitas vezes, não se sentem capazes de serem ajudados. Preferem destruir qualquer oferta de auxílio a ter que mergulhar em traumas que remetem ao início da infância. Isso ocorrerá, sobretudo, se o 
profissional for representado mentalmente como uma mãe incapaz de servir como referência para processos identificatórios.

Outro cenário igualmente pouco favorável ao processo terapêutico se constituirá se o profissional se tornar o objeto da projeção de uma figura paterna de valência negativa. Trata-se de um fenômeno bastante provável, se a figura paterna se mostrou inoperante no sentido de contornar as limitações da figura materna como agente do desenvolvimento da capacidade de simbolização do bebê. Ademais, para McDougall (1991), a figura materna de pacientes somáticos não raro atribuiu um quantum de afeto mínimo à figura paterna. Nesses casos, a figura paterna, destacada de seu papel fálico simbólico, inevitavelmente será representada como alguém que não merece ser amado.

A autora em pauta salienta que esses e outros expedientes protetores, dos quais pacientes somáticos inconscientemente podem lançar mão de modo sucessivo para sustentar a própria desafetação e obliterar o processo terapêutico, são necessários à manutenção do aparelho psíquico dos mesmos e devem, portanto, ser respeitados. Afinal, "[...] quanto mais um indivíduo for frágil em seu equilíbrio interno, mais ele lutará contra a pulverização de seus muros defensivos” (McDougall, 1989: 143). Tentativas de desarticular tais expedientes inadvertidamente, sem o consentimento dos pacientes, podem vir a potencializar suas dificuldades emocionais e descompensações somáticas.

Por fim, não se poderia deixar de abordar, no presente estudo, a questão da contratransferência. McDougall (1991) salienta que a clínica psicanalítica com pacientes somáticos tende a suscitar afetos negativos no profissional. Até porque, como mencionado, os mesmos comumente impõem uma série de obstáculos ao processo terapêutico, evitando o contato com a própria subjetividade e apelando a uma linguagem de impregnação simbólica restrita. Logo, com o passar do tempo, o profissional tende a se sentir dominado pela inércia psíquica característica da desafetação e, com isso, perder o prazer antes associado à prática de seu ofício.

Para subsidiar a superação de mais esse desafio inerente à clínica psicanalítica com pacientes somáticos, há que se colocar em relevo que, para McDougall (1989), a sintomatologia orgânica dos mesmos pode ser inserida no contexto de uma história que deve ser reconstituída mediante a substituição de seu palco do corpo pela mente. Um dos meios de se fazer isso é promover uma reconstituição de situaçõos de perda anteriores, incluindo-as em uma cadeia simbólica de modo a criar uma possibilidade de expressão para as emoções que não foram vivenciadas adequadamente quando da experiência original. 


\section{Discussão}

McDougall (1991) destaca que a desafetação guarda semelhanças com o pensamento operatório, descrito originalmente por Pierre Marty e Michel de M'Uzan. Os autores postularam que pacientes somáticos comumente apresentam um funcionamento psíquico que se situa entre as neuroses e as psicoses e cunharam tal termo para lhe fazer referência. Mas deve-se enfatizar que, ao contrário do que seria possível pensar a princípio, o pensamento operatório não é apenas uma modalidade de pensamento e, sim, um tipo de dinâmica mental (Peres, 2006). Ocorre que o pensamento operatório tende a se desdobrar em um marcante apagamento de toda expressividade emocional, por engendrar uma orientação excessiva à realidade externa e um apego demasiado à materialidade dos fatos (Marty \& M’Uzan, [1962] 1994).

A desafetação, todavia, pode ser considerada uma contribuição teórica original, visto que, ainda conforme Peres (2006), se diferencia do pensamento operatório em um aspecto principal. Ocorre que a desafetação possui um caráter essencialmente defensivo, ao passo que o pensamento operatório é atribuído a uma suposta carência funcional do psiquismo. Ou seja, trata-se de uma problemática estrutural. A substituição da simbolização pela reação biológica, quando da ocorrência de eventos potencialmente desestruturantes, seria, conforme Marty (1993), o corolário dessa problemática. Evidentemente, tal processo inviabiliza a formação de sintomas mentais e aumenta a vulnerabilidade somática do indivíduo.

A despeito de suas especificidades, a desafetação e o pensamento operatório representam, ambos, uma ampliação dos horizontes da teoria psicanalítica. Embora possa parecer óbvia, tal constatação muitas vezes é negligenciada em prol de exacerbações idiossincráticas. Estas, como observou Ferraz (1997), amiúde levam ao surgimento de resistências indevidas, no seio da psicanálise, às descobertas contemporâneas da psicossomática. McDougall e Marty não podem, portanto, ser acusados de renegarem suas origens freudianas.

A propósito, deve-se salientar ainda que a descrição da desafetação e do pensamento operatório privilegia a utilização do modelo etiológico das neuroses atuais - tal como definido em seus aspectos centrais na teorização freudiana - como referência para a exploração dos fatores emocionais associados à eclosão de doenças orgânicas. Justamente, em função dessa equivalência epistemológica, Peres (2006) sustenta que é possível estabelecer entre McDougall e Marty, dois dos principais nomes da psicossomática psicanalítica, uma relação de complementaridade em termos teóricos.

Não obstante, as implicaçôes práticas das contribuições teóricas dos referidos autores apontam caminhos relativamente distintos. McDougall defende a utilização 
da técnica psicanalítica clássica para pacientes somáticos que apresentam as características típicas da desafetação. Logo, o uso do divã, a realização de cinco sessões semanais e o emprego prioritário da interpretação são indicados. A autora deixa isso claro ao afirmar que "quer o postulante sofra de distúrbios psicossomáticos, de sintomas neuróticos, psicóticos ou caracteriais, quer de problemas de adicção, minha abordagem é a mesma" (McDougall, 1991: 5).

Já Marty (1993) afirma que, na clínica psicanalítica com pacientes somáticos que apresentam as características típicas do pensamento operatório, o profissional será convocado a assegurar as primeiras bases de uma proximidade bilateralmente identificatória. $\mathrm{O}$ autor esclarece que, para tanto, a realização das sessōes em situação face a face, nas quais o emprego de interpretações será restrito, pode ser imprescindível. Ademais, adverte que apenas uma sessão por semana é o mais adequado na maioria dos casos. Nesse sentido, sustenta que "a indicação de psicanálise clássica é muito limitada em psicossomática, por causa das frustrações que ela naturalmente implica" (Marty, 1993: 59).

Diversos psicanalistas, tais como Aisenstein (2005) e Santos Filho (1993), por exemplo, se alinham a essas diretrizes. Desse modo, argumentam em defesa do recurso do profissional a temas cotidianos, visando favorecer o exercício do pensamento por parte do paciente. A utilização sistemática de intervenções explicativas, capazes de auxiliar na compreensão de aspectos básicos do funcionamento mental, também é apontada como uma estratégia importante. Em contrapartida, a interpretação somente terá lugar quando não houver o risco de se colocar em relevo a insuficiência representacional do paciente.

Santos Filho (1993) salienta que o profissional deve assumir uma postura mais ativa e evitar a manutenção de longos períodos de silêncio, buscando com isso auxiliar o paciente somático a desenvolver recursos mais evoluídos de comunicação. A modulação de estados emocionais, por meio de cenários sugeridos com proposiçōes identificatórias é essencial para tanto (Aisenstein, 2005). Ou seja, deve-se instrumentalizar o paciente a nomear e expressar seus afetos, sobretudo em suas nuances e sutilezas. A exploração de equivalências, por ele estabelecidas, com sensaçôes corporais representa um importante ponto de partida.

McDougall e Marty, todavia, concordam que o exercício da função materna é imprescindível no contexto da clínica psicanalítica com pacientes somáticos, quer apresentem as características típicas da desafetação ou do pensamento operatório. Para Marty (1993: 64), a função materna consiste em "um acompanhamento sobretudo, mas não exclusivamente, verbal, que margeia, segue ou precede de perto os estados e movimentos do sujeito". Logo, consiste no oferecimento dos próprios sistemas elementares de representaçôes e defesas, bem como no desempenho pro- 
gressivo de funções fragilizadas do paciente e no abandono desses papéis quando dos primeiros sinais de independência.

Conforme McDougall (2001):

todo indivíduo deve conjugar a sua realidade psíquica, durante a vida, com o desejo primitivo de retorno ao estado de fusão com a mãe-universo: em outras palavras, com o desejo do não-desejo. A luta contra esse desejo e o luto que ela impõe são compensados, como todos nós sabemos, pela aquisição da identidade subjetiva (McDougall, 2001: 13).

Desempenhando adequadamente a função materna, o profissional que se dedica à clínica psicanalítica com pacientes somáticos será capaz de auxiliá-los nessa empreitada. Como consequência, poderá torná-los capazes de concluir o processo de dessomatização do aparelho psíquico que não pôde ser levado a termo durante a infância.

\section{CONSIDERAÇÕES FINAIS}

Adotou-se a noção de desafetação como operador conceitual básico do presente estudo, visando estabelecer um panorama, em termos teóricos e clínicos, da concepção psicossomática de McDougall. Tal opção metodológica justifica-se, sobretudo, porque a referida noção, central para a autora em pauta, ainda não foi totalmente incorporada ao vocabulário psicanalítico. O presente estudo pode auxiliar a reverter essa situação, servindo como uma leitura inicial aos interessados no funcionamento psíquico e no manejo clínico de pacientes somáticos, à luz de um dos desenvolvimentos pós-freudianos mais importantes. Porém vale destacar que, obviamente, o aprofundamento dos temas ora abordados demanda um percurso por toda a instigante obra de McDougall.

Ao longo do presente estudo foram feitas referências pontuais ao modelo teórico de Marty, com o intuito de tornar mais clara a especificidade da concepção psicossomática de McDougall. Para uma melhor compreensão das convergências e divergências teóricas entre ambos, a revisão de Casetto (2006) se apresenta como uma indicação pertinente. À guisa de conclusão, todavia, parece oportuno mencionar que tal revisão esclarece que Marty forjou a noção de pensamento operatório a partir da prática clínica no contexto hospitalar. Já McDougall, criou a noção de desafetação face às observações executadas em pacientes atendidos em consultório, 
que adoeciam durante o processo. Essa diferença, no que se refere à casuística, pode ser uma das razões das divergências entre os autores em pauta.

\section{REFERÊNCIAS}

Aisenstein, M. (2005). Abordagem psicodinâmica do paciente psicossomático. In: Eizirik, C. L., Aguiar, R. W. \& Schestatsky, S. (Orgs.). Psicoterapia de orientação analítica: fundamentos teóricos e clínicos (pp. 667-673). (Trad. C. Monteiro). Porto Alegre: ArtMed.

Bunemer, E. (1995). Desafetação: a dificuldade de investir no objeto. IDE, 26, 28-42.

Casetto, S. J. (2006). Sobre a importância do adoecer: uma visão em perspectiva da psicossomática psicanalítica no século XX. Psychê, 17, 121-142.

Ceccarelli, P. R. (1997). Joyce McDougall: uma apresentação. Percurso, 18, 104-106.

Ferenczi, S. (1940/1988). Escritos psicanalíticos: 1909-1933 (Trad. J. Bastos \& A. Telles). Rio de Janeiro: Taurus.

Ferraz, F. C. (1997). Das neuroses atuais à psicossomática. In: Ferraz, F. C. \& Volich, R. M. (Orgs.). Psicossoma: psicossomática psicanalítica (pp. 23-38). São Paulo: Casa do Psicólogo.

Freud, S. (1893/1996). Algumas considerações para um estudo comparativo das paralisias motoras orgânicas e histéricas. Obras completas, ESB, v. III. Rio de Janeiro: Imago.

Freud, S. (1894a/1996). As neuropsicoses de defesa. Obras completas, ESB, v. III. Rio de Janeiro: Imago.

Freud, S. (1894b/1996). Carta 18. Obras completas, ESB, v. I. Rio de Janeiro: Imago.

Freud, S. (1895/1996). Sobre os fundamentos para destacar da neurastenia uma síndrome específica denominada "neurose de angústia". Obras completas, ESB, v. III. Rio de Janeiro: Imago.

Freud, S. (1908/1996). Fantasias histéricas e sua relação com a bissexualidade. Obras completas, ESB, v. IX. Rio de Janeiro: Imago.

Freud, S. (1911/1996). Sobre o narcisismo: uma introdução. Obras completas, ESB, v. XIV. Rio de Janeiro: Imago.

Groddeck, G. (1917/1992). Estudos psicanaliticos sobre psicossomática. São Paulo: Perspectiva.

Horn, A. \& Almeida, M. C. P. (2003). Sobre as bases freudianas da psicossomática psicanalítica: um estudo sobre as neuroses atuais. Revista Brasileira de Psicanálise, 37(1), 69-84.

Lacan, J. (1966/1992). Escritos. São Paulo: Perspectiva.

Laplanche J. \& Pontalis, J. B. (1982/2000). Vocabulário da psicanálise. São Paulo: Martins Fontes. 
Marty, P. (1993). A psicossomática do adulto. Porto Alegre: Artes Médicas.

Marty, P. \& M'Uzan, M. (1962/1994). O pensamento operatório. Revista Brasileira de Psicanálise, 28(1), 165-174.

McDougall, J. (1983). Em defesa de uma certa anormalidade. Porto Alegre: Artes Médicas.

McDougall, J. (1989). Teatros do eu. Rio de Janeiro: Francisco Alves.

McDougall, J. (1991). Teatros do corpo. São Paulo: Martins Fontes.

McDougall, J. (2001). Um corpo para dois. In: McDougall, J., Gachelin, G., Aulagnier, P., Marty, P., Loriod, J. \& Caïn, J. (Orgs.). Corpo e história (pp. 9-46). São Paulo: Casa do Psicólogo.

Peres, R. S. (2005). A psicanálise no divã. Paidéia, 15, 309-311.

Peres, R. S. (2006). O corpo na psicanálise contemporânea: sobre as concepções psicossomáticas de Pierre Marty e Joyce McDougall. Psicologia Clinica, 18(1), 165-177.

Roudinesco, E. (1986). História da psicanálise na França: a batalha dos cem anos. Rio de Janeiro: Jorge Zahar.

Santos Filho, O. C. (1993). Psicoterapia psicanalítica do paciente somático. In: Mello Filho, J. (Org.). Psicossomática hoje (pp. 353-361). Porto Alegre: Artes Médicas.

Schiller, P. (2003). As psicossomáticas. In: Volich, R. M., Ferraz, F. C. \& Rañna, W. (Orgs.). Psicossoma III: interfaces da psicossomática (pp. 27-31). São Paulo: Casa do Psicólogo.

Volich, R. M. (1998). Fundamentos psicanalíticos da clínica psicossomática. In: Volich, R. M., Ferraz, F. C. \& Arantes, M. A. A. C. (Orgs.). Psicossoma II: psicossomática psicanalítica (pp. 17-31). São Paulo: Casa do Psicólogo.

Recebido em 22 de julho de 2009 Aceito para publicação em 21 de maio de 2010 